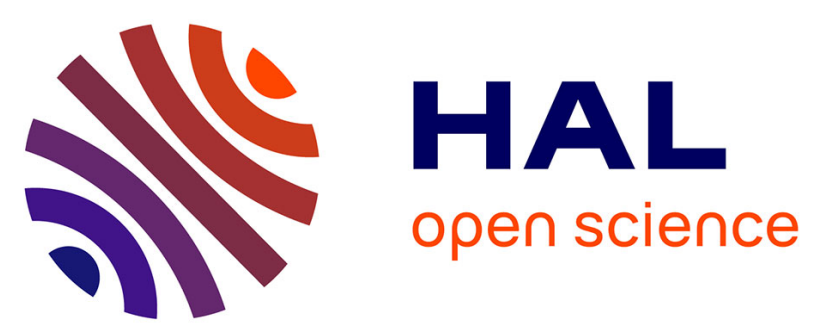

\title{
Percolation behavior of Ag in Ge16Sb12Se72 glassy matrix and its impact on corresponding ionic conductivity
}

Deepak Patil, Manisha Konale, Solenn Cozic, Laurent Calvez, Vitezslav Zima, Tomas Wagner, John S Mccloy, David Le Coq

\section{To cite this version:}

Deepak Patil, Manisha Konale, Solenn Cozic, Laurent Calvez, Vitezslav Zima, et al.. Percolation behavior of Ag in Ge16Sb12Se72 glassy matrix and its impact on corresponding ionic conductivity. Journal of Alloys and Compounds, 2019, 782, pp.375-383. 10.1016/j.jallcom.2018.12.140 . hal-01990469

HAL Id: hal-01990469

https://hal-univ-rennes1.archives-ouvertes.fr/hal-01990469

Submitted on 23 Jan 2019

HAL is a multi-disciplinary open access archive for the deposit and dissemination of scientific research documents, whether they are published or not. The documents may come from teaching and research institutions in France or abroad, or from public or private research centers.
L'archive ouverte pluridisciplinaire HAL, est destinée au dépôt et à la diffusion de documents scientifiques de niveau recherche, publiés ou non, émanant des établissements d'enseignement et de recherche français ou étrangers, des laboratoires publics ou privés. 


\title{
Percolation behavior of $\mathrm{Ag}$ in $\mathrm{Ge}_{16} \mathrm{Sb}_{12} \mathrm{Se}_{72}$ glassy matrix and its impact on corresponding ionic conductivity
}

\author{
Deepak S. Patil ${ }^{\mathrm{a}, \mathrm{b},{ }^{,}}$, Manisha Konale ${ }^{\mathrm{c}}$, Solenn Cozic ${ }^{\mathrm{d}}$, Laurent Calvez ${ }^{\mathrm{d}}$, Vitezslav Zima ${ }^{\mathrm{e}}$, Tomas Wagner ${ }^{\mathrm{c}}$, John S. \\ McCloy ${ }^{\mathrm{b}}$, David Le Coq ${ }^{\mathrm{d}}$ \\ a Department of Chemistry, New Mexico Highlands University, Las Vegas, NM 87701, USA \\ ${ }^{b}$ School of Mechanical \& Materials Engineering, Washington State University, Pullman, WA 99164, USA \\ 'Department of General and Inorganic Chemistry, Faculty of Chemical Technology, University of \\ Pardubice, Studentska 95, Pardubice, 53210, Czech Republic \\ dInstitut des Sciences Chimiques de Rennes, Eq. Verres et Céramiques, UMR 6226 CNRS, Université de \\ Rennes 1, 35042 Rennes Cedex, France \\ e Institute of Macromolecular Chemistry of the Czech Academy of Sciences, Heyrovskeho nam. 2, 16206 \\ Prague 6, Czech Republic \\ *Corresponding author: dspatil@nmhu.edu
}

\begin{abstract}
In the present article, the silver diffusion behavior and its influence on ionic conduction have been studied from a series of glass samples $\mathrm{Ag}_{x}\left(\mathrm{Ge}_{16} \mathrm{Sb}_{12} \mathrm{Se}_{72}\right)_{100-x}$ with $0 \leq x \leq 25$. A non-linear evolution of the ionic conduction as a function of $\mathrm{Ag}$ concentration was found and attributed to a variation in the diffusion mechanism following the $\mathrm{Ag}$ rate. The glasses with $\mathrm{Ag}$ concentration lower than 5 at. \% i.e. for $\mathrm{Ag}_{0.2}$ to $\mathrm{Ag}_{1}$, the $\mathrm{Ag}^{+}$diffusion mainly occurs via a percolation mechanism, whereas for the $\mathrm{Ag}$ concentration from $\mathrm{Ag}_{5}$ up to $\mathrm{Ag}_{15}$, a hopping mechanism is prevailing. However, for Ag5 the diffusion occurs with mixed mechanism i.e. percolation + hopping way. For the Ag content higher than 15 at. \% the diffusion occurs via a correlated walk and it was found that the repulsive nature between the $\mathrm{Ag}^{+}$ions in the high concentrated sample due to much shorter distance does not show self-blocking nature. Additionally, the samples show a transition from electronic to ionic conductivity. From Raman analysis a correlation between the content of $\mathrm{Ag}$ and the type of $\mathrm{GeSe}_{4 / 2}$ tetrahedron, corner or edgeshared, which takes place in the structure, was evidenced. Finally, the results allow a better understanding of the mechanism of the Ag conduction in the glasses of the Ge-Sb-Se system using the RW model.
\end{abstract}

\section{Keywords}

Percolation behavior, diffusion coefficient, ionic conductors, impedance spectroscopy, chronoamperometry, hopping mechanism

\section{Introduction}

Chalcogenide glasses (ChGs) have unique optical and electrical properties, making them potential candidates for many applications [1]. From the optical point of view, the wide transparency window from the visible up to more than $30 \mu \mathrm{m}$ originates the development of 
many infrared technologies from fibres [2, 3], buried waveguides [4, 5], and thin films [6, 7], dedicated photonic applications[8]. Nevertheless, the ChGS applications are not limited to the optical field since they also have many interesting electrical properties. As examples, applications are found in solid-state batteries [9-11], ionic memories [12], selective ion conducting membranes $[13,14]$. The interest in ChGs is mainly due to their higher ionic conductivity than their oxide counterparts $[11,15]$. Due to the higher electronegativity of oxygen compared to chalcogen elements, the ionic character of the bond in oxide glasses hinders cationic motion compared to the chalcogenide glasses. The structural and electrostatic interactions in oxide glasses result in a higher activation energy and consequently in a lower ionic conductivity of the oxide glasses. In addition to a lower activation energy with higher ionic conductivity, ChGs have the wide compositional flexibility and ease of fabrication, which creates attention of the researcher towards ChGs for the development of solid-state ionic conductors [16-18]. Despite the alkali metal-doped ( $\mathrm{Li}, \mathrm{Na}$ ) ChGs show high current density and high ionic conductivity [19], they are often criticized for their thermal safety issues [20, 21]. Cudoped chalcogenides show lower ionic conduction than those with an equal amount of Agdoped corresponding chalcogenide matrix [17]. The benefits of $\mathrm{Ag}^{+}$-ion conducting glass electrolytes are lower susceptible to moisture sensitivity and an equal or higher power density with current Lithium ion battery. Consequently, Ag-based ChGs can be considered as promising materials for solid-state ionic conductors employed in ionic batteries and for other ion conducting material applications with considered being the most reliable and stable batteries [22].

Moreover, Ge- and Se-based glass systems have a wide glass-forming region with a wide compositional flexibility, allowing the high amount of ion addition without affecting its amorphous nature. Also, the addition of $\mathrm{Sb}$ in this Ge-Se matrix reduces the number of homopolar bonds in the Se rich systems and increases the reticulation of the network, allowing an increase of the thermal stability of these glassy systems [23]. In this prospective, in the current study, we have selected $\mathrm{Ge}_{16} \mathrm{Sb}_{12} \mathrm{Se}_{72}$ as a matrix in which Ag is added and investigated the ion conducting behavior as a function of $\mathrm{Ag}$ concentration. The electrical properties of the current system $\mathrm{Ag}_{\mathrm{x}}\left(\mathrm{Ge}_{16} \mathrm{Sb}_{12} \mathrm{Se}_{72}\right)_{100-x}$ are studied by means of impedance spectroscopy (IS) and an analysis by a random-walk (RW) model is proposed $[9,24]$. This RW model provides consistent information on total ionic conductivity or activation energy value similar to EEC model, but also provides a quantitative information about the diffusion coefficient and the concentration of the mobile ions. Such quantitative information cannot be obtained through conventional equivalent electric circuit $(E E C)$ model $[9,24]$. In the end, a correlation between the conduction mechanism of the mobile $\mathrm{Ag}^{+}$ion and the structure is proposed.

\section{Experimental Methods}

The samples having composition $\mathrm{Ag}_{x}\left(\mathrm{Ge}_{16} \mathrm{Sb}_{12} \mathrm{Se}_{72}\right)_{100-x}$ with $0 \leq x \leq 25$, were prepared by the conventional melt quenching method. All the elements $(\mathrm{Ag}, \mathrm{Ge}, \mathrm{Sb}, \mathrm{Se})$ used for the synthesis were of high purity $5 \mathrm{~N}$. A batch of $10 \mathrm{~g}$, with an appropriate amount of each element was sealed in a quartz ampule (with the inner diameter of $10 \mathrm{~mm}$ ) under high vacuum $\left(10^{-3} \mathrm{~Pa}\right)$. The mixture of the elements in the sealed ampule was heated with a rate $2^{\circ} \mathrm{C} / \mathrm{min}$ up to $950^{\circ} \mathrm{C}$ before dwelling at $950^{\circ} \mathrm{C}$ for $12 \mathrm{~h}$ in a rocking furnace. Next, the temperature was slowly cooled down to $730{ }^{\circ} \mathrm{C}$ before quench in water, and an annealing at a temperature close to $T_{\mathrm{g}}$ for $4 \mathrm{~h}$ following by slow cooling down to room temperature were performed to reduce the internal stresses and strains. The obtained glass rods were cut into discs of $10 \mathrm{~mm}$ diameter and a thickness between 1-2 $\mathrm{mm}$. The glass discs were polished with optical quality using SiC papers as well as $\mathrm{Al}_{2} \mathrm{O}_{3}$ powder with varying sizes such as $6 \mu \mathrm{m}, 3 \mu \mathrm{m}$, and $1 \mu \mathrm{m}$. For electrical 
measurements, the polished disks were sputtered with gold on both sides for a good electrical contact with the electrodes as well as to form a blocking electrode.

Differential scanning calorimetry (DSC Perkin-Elmer Pyris 1) with a heating rate of $10{ }^{\circ} \mathrm{C} \cdot \mathrm{min}^{-1}$ was used for measuring the characteristic temperatures of glass samples. $5 \mathrm{mg}$ of powder of each sample with particle size $<125 \mu \mathrm{m}$ were placed in an aluminium pan for the DSC measurement. The determination of crystalline or amorphous nature XRD analysis were performed with $\mathrm{D} 8$ - advance $\mathrm{Cu}$ anode in the angle range of $2 \theta$ between $5^{\circ}$ and $90^{\circ}$ with a step of $0.02^{\circ}$.

Electrical properties were analyzed using impedance spectroscopy (IS), carried out on a PGSTAT $302 \mathrm{~N}$ with the FRA32 and NOVA 10 software. The cell used stainless disk-like electrodes sputtered with gold to block the $\mathrm{Ag}^{+}$ions passage. Temperature dependence IS was carried out with an applied input voltage of $0.1 \mathrm{~V}$, the temperature range from $298 \mathrm{~K}$ to $368 \mathrm{~K}$, and a frequency range from $1 \mathrm{~Hz}$ to $50 \mathrm{KHz}$. The temperature was controlled with a Microcell $\mathrm{HC}$ setup (Rhd instruments) with an accuracy of $\pm 1{ }^{\circ} \mathrm{C}$. The input capacitance and impedance of the instrument were lower than $8 \mathrm{pF}$ and higher than $100 \mathrm{G} \Omega$, respectively. Moreover, DCchronoamperometric measurements were also performed with the same instrument, and a constant voltage of $100 \mathrm{mV}$ was applied to investigate the ionic and electronic contribution to the total electrical conductivity of the glass samples.

\section{Results and discussion}

As mentioned earlier, the present mother/baseline matrix $\mathrm{Ge}_{16} \mathrm{Sb}_{12} \mathrm{Se}_{72}$ was selected because of its high glass forming ability (expecting higher Ag incorporation) and good thermal stability [25]. From a visual observation, all prepared glasses show dark shiny black color as shown in Fig. S1. It is interesting to note that, even at 25 at.\% of $\mathrm{Ag}$ concentration sample, still able to obtain nice shiny glass rod. This indicates the high glass forming and the high incorporation ability of the $\mathrm{Ge}_{16} \mathrm{Sb}_{12} \mathrm{Se}_{72}$ matrix.

The prepared series can be represented by general chemical formula $\mathrm{Ag}_{x}\left(\mathrm{Ge}_{16} \mathrm{Sb}_{12} \mathrm{Se}_{72}\right)_{100-x}$; for easier reading each sample is denoted $\mathrm{Ag}_{x}$, where $x$ is the molar concentration of $\mathrm{Ag}$ in the corresponding sample. The sample denotation and the corresponding sample composition are given in Table S1.

\subsection{XRD analysis}

From Fig. 1 , it is clear that all samples are in fully amorphous nature except $\mathrm{Ag}_{25}$, which is partially crystallized and where an unknown crystalline phase was observed. Due to this fact, the $\mathrm{Ag}_{25}$ sample was not characterized further and not compared to other glasses of the series. 


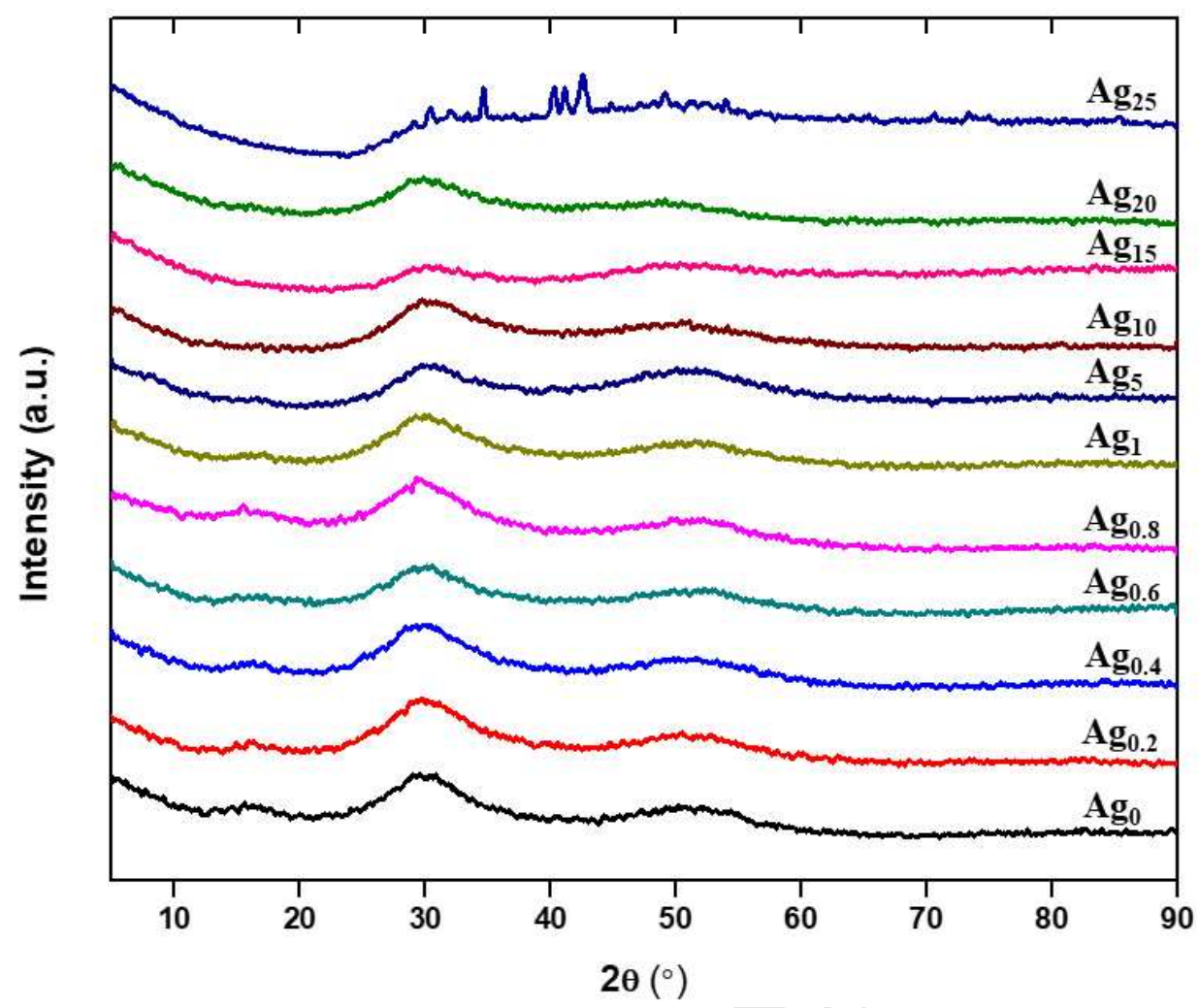

Fig. 1 XRD pattern of $\mathrm{Ag}_{x}\left(\mathrm{Ge}_{16} \mathrm{Sb}_{12} \mathrm{Se}_{72}\right)_{100-x}$ series from $\mathrm{Ag}_{0}$ to $\mathrm{Ag}_{25}$.

\subsection{Thermal Behavior}

The evolution of the glass transition temperature $(\mathrm{Tg})$ of the samples as a function of the content of $\mathrm{Ag}$ shows a nonlinear behavior as shown in Fig. 2. Tg first decreases as the $\mathrm{Ag}$ content increases from 0 to 10 at.\%, then Tg remains constant from 10 at.\% to 15 at.\%. The decrease of $\mathrm{Tg}$ at low content of $\mathrm{Ag}$ was expected because of $\mathrm{Ag}$ nature as a modifier. The saturation of $\mathrm{Tg}$ at higher concentrations of $\mathrm{Ag}$, namely $>10$ at.\% may be ascribed to a clustering of $\mathrm{Ag}$ instead of structural modification or a different role of Ag. Nevertheless, at this stage, it is difficult to have consistent conclusions and the further Raman analyses will be more instructive. 


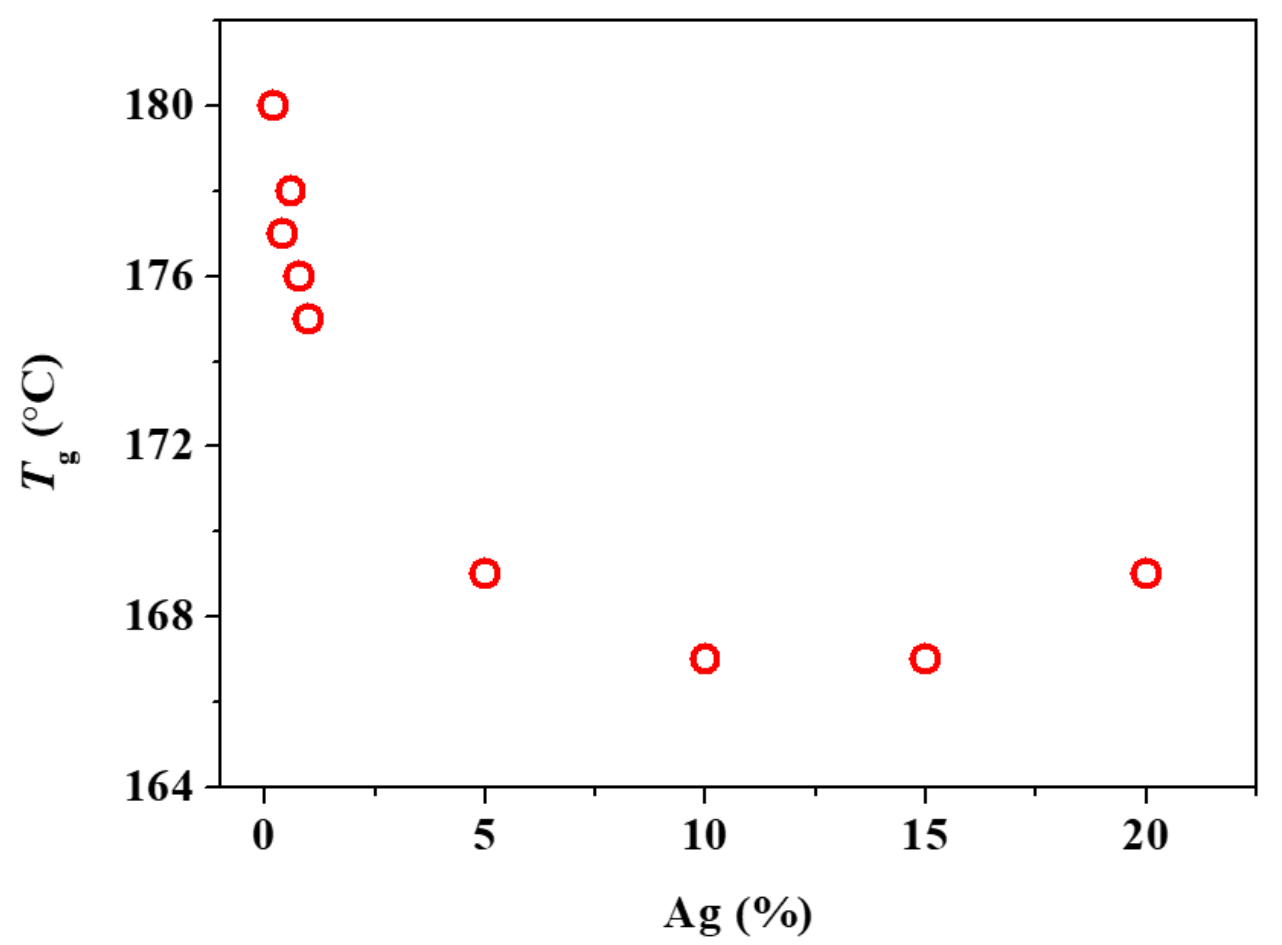

Fig. $2 \mathrm{Tg}$ of the glasses shown as a function of Ag concentration.

\subsection{Electrical Behavior}

The glass samples with a lower content of $\mathrm{Ag}$, i.e. $\leq 1$ at.\% show lower conductivity than $10^{-11}$ $\mathrm{S} \cdot \mathrm{cm}^{-1}$ at $298 \mathrm{~K}$, which is outside the limit of the used impedance instrument. This is the reason to compare the electrical properties of all samples, that is their resistivity (Fig. S2) as well as the dependence of real $\left(\sigma_{1}\right)$ and imaginary $\left(\sigma_{2}\right)$ part of conductivity on frequency $(\omega)$ (Fig. 3a and Fig. 3b, respectively) shown at $368 \mathrm{~K}$.

The real and imaginary parts of the resistivity, $\rho_{1}$ and $\rho_{2}$, respectively, were deduced from the following simple relation of $Z_{1}$ and $Z_{2}$ with taking into account the dimensions of the sample:

$\rho_{1}=Z_{1} A / L$ and $\rho_{2}=Z_{2} A / L$,

where $A$ is the surface area of an electrode and $L$ is sample thickness. For the low $\mathrm{Ag}$ content, i.e. $\mathrm{Ag}<1 \%$, the conductivity even at $368 \mathrm{~K}$ is still at the edge of the current IS instrument measurement limit. This is the reason why the obtained impedance/resistivity data of the lower $\mathrm{Ag}$ containing samples were scattered/dispersed in comparison with the samples containing higher amount of $\mathrm{Ag}$ and this difference is clearly shown in a complex impedance plot of resistivity in Fig. S2. To confirm this scattering/dispersion behavior, either due to instrument limitation or measured glass samples intrinsic property, we have tested an equivalent commercial resistor and obtained similar results. This confirms that the scattering in the impedance data is not due to any material intrinsic property.

In Fig. S2, as expected, the size of semicircle decreases with the increase of the $\mathrm{Ag}$ concentration, which indicates that the conductivity increases from $\mathrm{Ag}_{0}$ to $\mathrm{Ag}_{20}$. In Fig. S2, there 
are two important points worths to be mentioned: 1) in our previous study on $\mathrm{Ag}_{x}\left(\mathrm{Ge}_{28} \mathrm{Sb}_{12} \mathrm{Se}_{60}\right)_{100-x}$, for $\mathrm{Ag}=0$, i.e. for $\mathrm{Ge}_{28} \mathrm{Sb}_{12} \mathrm{Se}_{60}$, the conductivity beyond the instrument measurement limit occurs at the same temperature [17] (the measurement of IS data has been done on the same instrument), but here the $\mathrm{Ag}_{0}$ sample shows within instrument measurement limits, which clearly indicates that the electronic conductivity (as there is no $\mathrm{Ag}$ in the mother matrix, so, the conductivity increases due to electronic + hole contribution only) increases with Se concentration increases and the Ge concentration decreases in GeSbSe system (considering $\mathrm{Sb}$ concentration constant). 2) Unlike in the case of $\mathrm{Ag}$ doped sulfide glasses [10, 24], no tail was observed at the low frequency side of the above complex impedance plot (Fig. S2), even at $\mathrm{Ag}$ concentrations up to $20 \%$. It is known that the high-frequency semicircle relates to the electronic properties of the bulk region of the sample and the low frequency tail relates to the electrode polarization at the interface of the electrode surface and the sample. The polarization tail will form due to the blocking of ions on the electrode surface. In the current study, the absence of a tail on the low frequency side may be due to the low ionic conductivity or the fact that the cations while diffusing towards -ve electrode recombines with the electrons which again responsible for reducing the concentration of total cations. Either of this situation or both are responsible for the depletion of electrode polarization and responsible for the absence of a tail.

The above resistivity data were further converted into real $\left(\sigma_{1}\right)$ and imaginary $\left(\sigma_{2}\right)$ parts of the conductivity according to the well-known relation[9] as

$\sigma_{1}=\frac{\rho_{1}}{\rho_{1}^{2}+\rho_{2}^{2}}$ and $\sigma_{2}=\frac{\rho_{2}}{\rho_{1}^{2}+\rho_{2}^{2}}$

The obtained conductivities $\sigma_{1}$ and $\sigma_{2}$ are plotted against applied angular frequency $\omega(\omega=2 \pi f)$ and shown in Fig. $3 a$ and $3 b$ respectively.
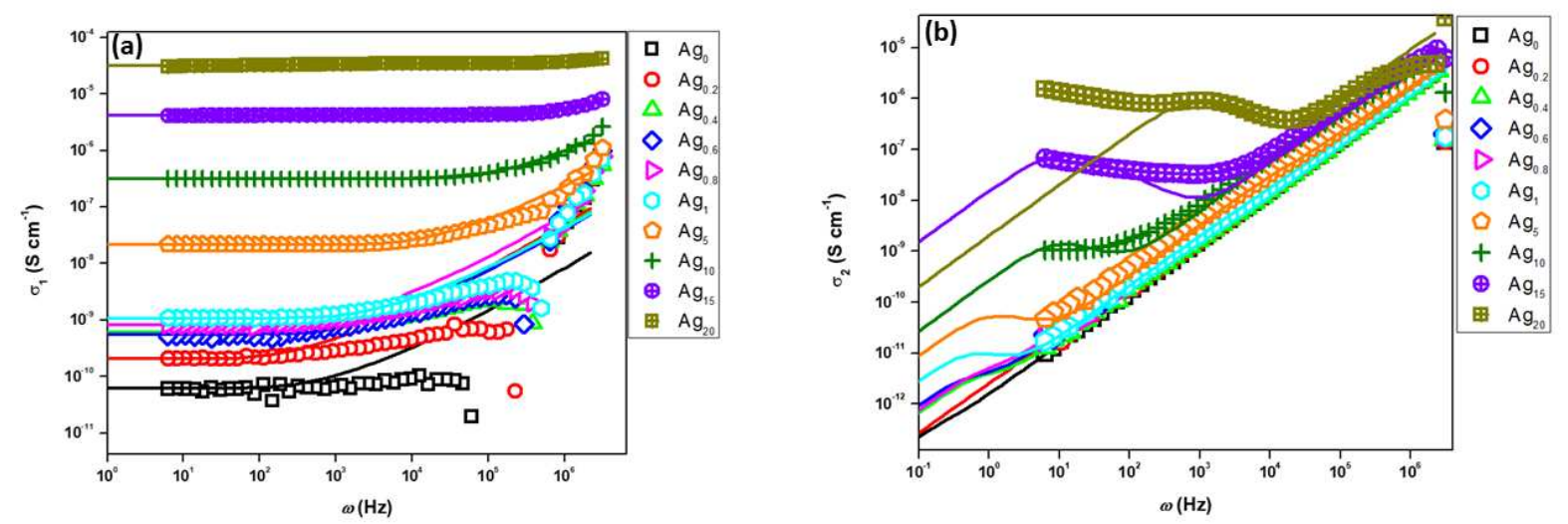

Fig. 3 a) The real part of conductivity $\sigma_{1}$ and $\mathbf{b}$ ) the imaginary part of conductivity $\sigma_{2}$ as a function of the sample composition at $368 \mathrm{~K}$. Open symbols represent the experimental data, the solid lines represents the $R W$ model fitting. 
In Fig. 3a, the real part of conductivity $\sigma_{1}$ was plotted as a function of $\omega$. The observed constant plateau represents the total electrical conductivity $\sigma_{T}$ (ionic + electronic) of the sample at the temperature of measurement $(368 \mathrm{~K})$. From Fig. 3a, it is clear that $\sigma_{T}$ increases with the $\mathrm{Ag}$ concentration, i.e. from $\mathrm{Ag}_{0}$ to $\mathrm{Ag}_{20}$. As expected from the complex impedance plot, the low frequency bending which arises due to the electrode polarization [18] is not observed in the real part of conductivity of all samples. Nevertheless, there is a small hump observed in the imaginary part of the $\mathrm{Ag}_{20}$ sample, which is typical sign for electrode polarization at electrodeelectrolyte interface [9]. It is worth to note that, in typical homogeneous ionic conductors, after the hump in imaginary part of conductivity, the data shows continuous decrease but in the case of $\mathrm{Ag}_{20}$ the data shows again increase (see Fig. $3 \mathrm{~b}$ ) which could be due to either a grain boundary effect or a phase separation .

The total conductivity $\sigma_{T}$ also called DC conductivity (due to frequency independent nature in the $\sigma_{1}$ plot, i.e. the constant plateau region), was plotted as a function of $\mathrm{Ag}$ concentration (Fig. 4).

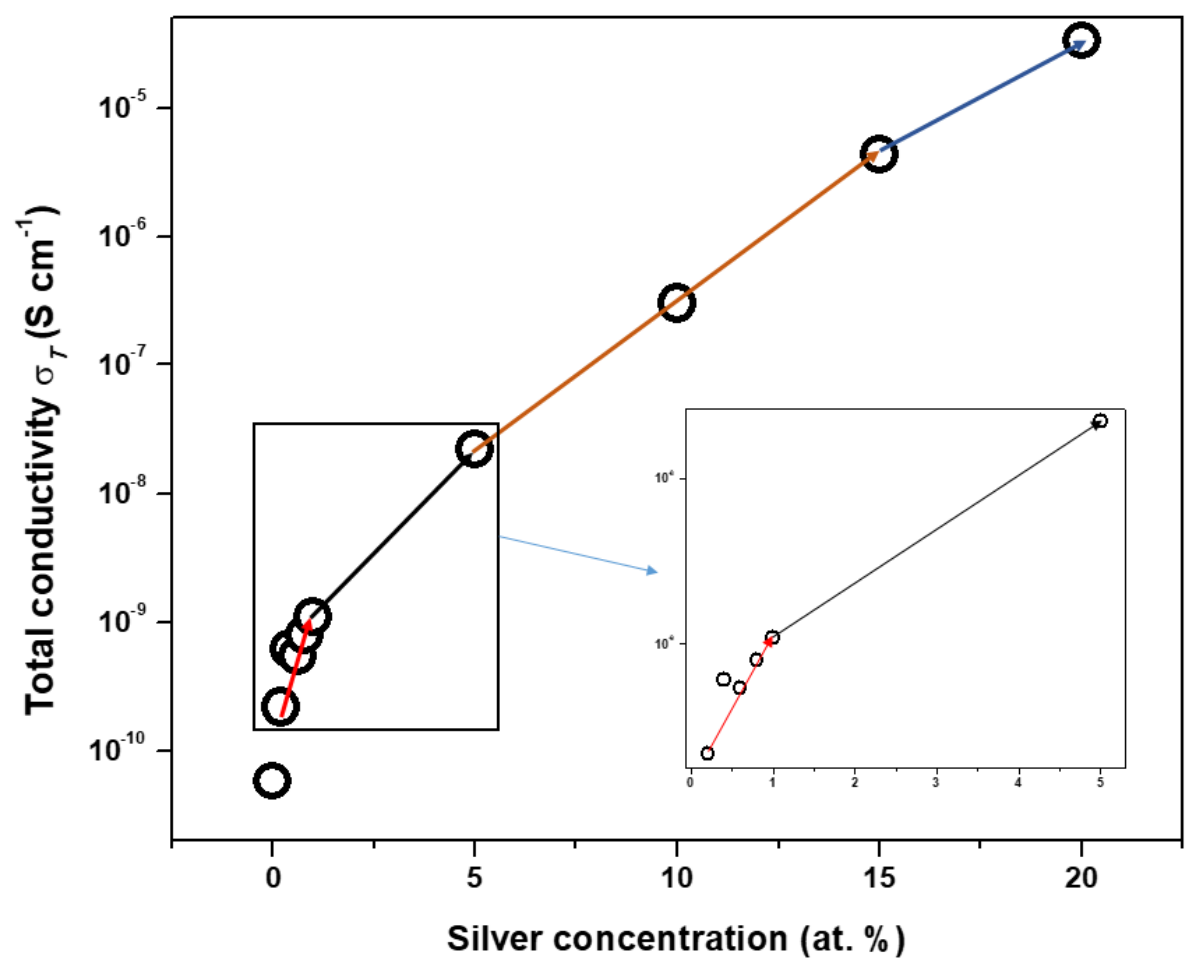

Fig. 4 The total conductivity $\left(\sigma_{T}\right)$ as a function of $\mathrm{Ag}$ concentration at $368 \mathrm{~K}$. Inset shows magnified image of the marked area. Open symbols represents the experimental value whereas solid line colored arrows represents the guideline for eyes.

It can be observed that the total conductivity $\sigma_{T}$ shows a non-linear growth with $\mathrm{Ag}$ concentration. The slope of conductivity vs. Ag concentration decreases with increasing content of Ag. This non-linear ionic conductivity behavior has already been described by other authors 
on similar family of glass (Ag-Ge-Sb-Se) $[17,26]$. However, the conductivity behavior in the AgAsSe system was found to be different in comparison to AgGeSbSe system [27]. The AgAsSe system showed different behavior than AgGeSbSe system such as AgAsSe shows electronic to ionic transition at very low Ag doping. Also, the Ag-As-Se system shows a saturation behavior of ionic conductivity at a much lower Ag concentration ( 10 at\%) compared to GeSbSe system due to the micro-phase separation in the system. Such phase separation observed in the studied system at Ag concentrations $\geq 25$ at $\%$.

The nonlinear behavior of conductivity in Fig. 4, specially transition of the conductivity slope from low ( $\leq 1$ at.\%) to medium ( $\leq 15$ at.\%) amount of $\mathrm{Ag}$, was explained by Stehlik et al. [27] as an electronic to ionic transition in the Ag-As-Se system, which is not the case of the currently studied sample. If there were an electronic to ionic transition, it could be expected for low $\mathrm{Ag}$ concentrations ( $\leq 1$ at.\%), that the conductivity would not increase sharply with a slight variation in $\mathrm{Ag}$ concentration (for example from 0.2 to 0.4 or 0.4 . to 0.6 at.\%, etc.). In an electronic conductivity system, it can be expected that in addition of cations, the total conductivity either decreases or is constant. This is contradictory to the current observation, indicating that the non-linear behavior does not arise from the electronic to ionic transition. It can be clearly observe in Fig. 4, the conductivity increases sharply for $\mathrm{Ag}_{0.2}$.to $\mathrm{Ag}_{1}$, whereas further increase of $\mathrm{Ag}$ doping concentration, the conductivity shows clear transition (see inset image of Fig. 4). Changes in slopes with Ag concentrations were marked by different arrows in Fig. 4. These changes in slopes were clear sign of non-linear behavior and could be due to different role/mechanism of $\mathrm{Ag}$ conduction. Further details of the non-linear behavior of the ionic conduction will be explained in the following section based on the diffusion coefficient.

\subsubsection{Mobile ion concentration $(N)$ and Diffusion Coefficient $(D)$}

As shown in Fig. $3 a$ and $3 b$, the experimental data are nicely fitted with a Random-walk (RW) model. Using this RW model fitting, we calculated the concentration of the mobile ions $(N)$ and the diffusion coefficient $(D)$ using Eqs. 2 and 3 respectively [24].

$\sigma_{T}=\frac{N(e R)^{2}}{6 k T \tau_{m}}$

And $D=\frac{R^{2}}{6 \tau_{m}}$,

where $R$ and $\tau_{\mathrm{m}}$ are the hopping distance (is the average distance of ions hopped from one site to another site) and the maximum hopping time of ions, respectively. The obtained results are plotted as a function of the concentration of $\mathrm{Ag}$, as shown in Fig. 5. 


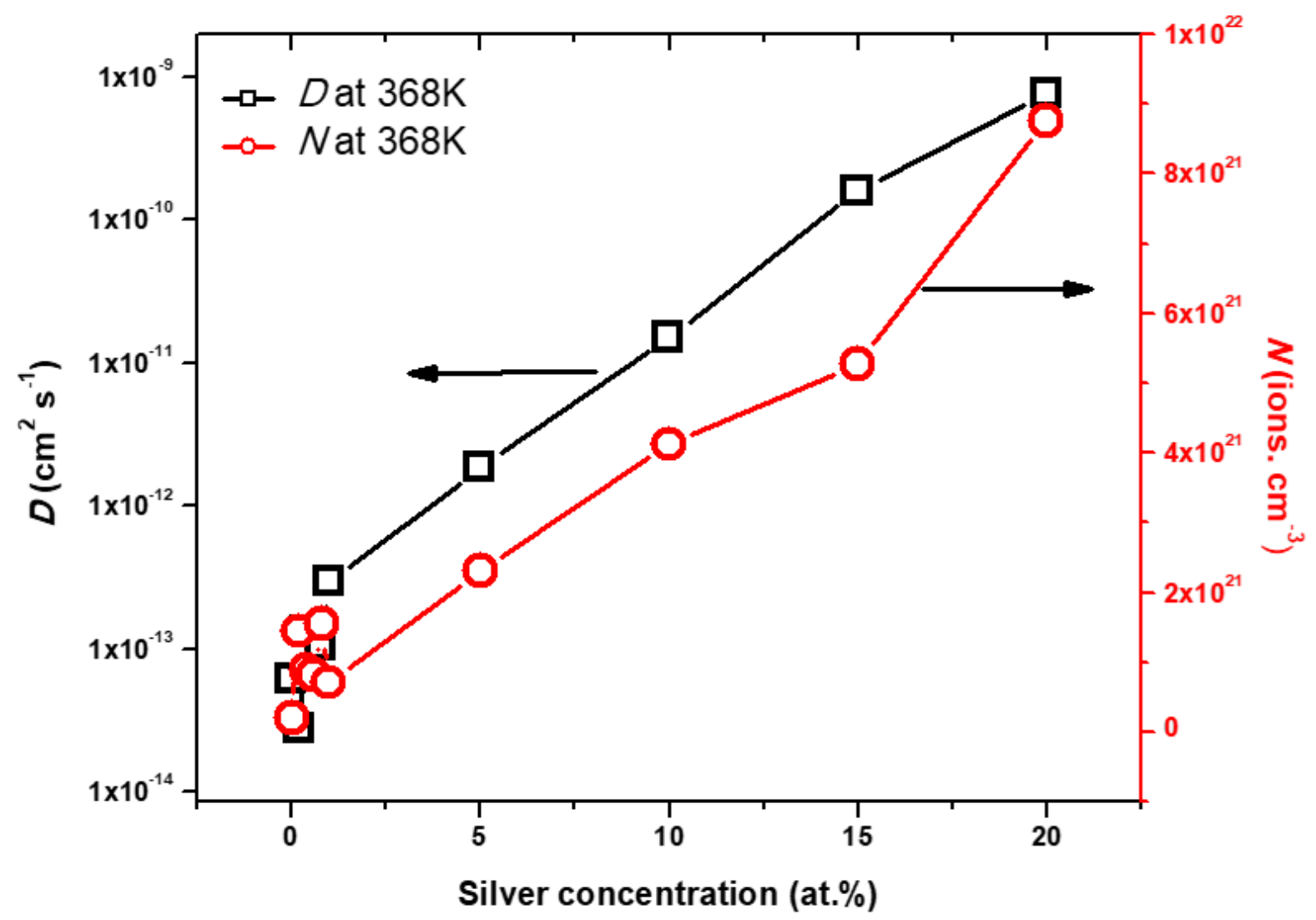

Fig. 5 The diffusion coefficient $(D)$ and the mobile ion concentrations $(N)$ calculated using $R W$ model plotted as a function of $\mathrm{Ag}$ concentration at $368 \mathrm{~K}$. Open symbols represent the calculated values whereas solid line represent the guideline for eyes.

It is surprising to see in Fig. 5, that the diffusion coefficient $(D)$ shows exact same trend like as the conductivity shown in Fig. 4, whereas the mobile ion concentration $(N)$ is scattered for low $\mathrm{Ag}$ content ( $<1$ at.\%). However, at higher concentration of $\mathrm{Ag}(\geq 5$ at.\%), $N$ shows nearly similar pattern like $D$. This indicates that, the conductivity is dominated by the diffusion coefficient; it means that the diffusion coefficient is predominantly responsible for the conductivity behavior.

From Fig. 5, the diffusion coefficient behavior can be divided into three regions depending on the $\mathrm{Ag}$ atomic concentration the in samples: i) low ( $\leq 1$ at.\%) ii) medium ( $\leq 15$ at.\%), and (iii) high (> 15 at.\%) concentration of Ag. It is known that defects/disorder in materials are a keyfactor influencing the diffusion coefficient of cations in the solid-state materials [28]. As mentioned earlier in Fig. 2, the Tg decrease, saturation and further increase are directly related to the increase, saturation and decrease of the defects, respectively. This is due to the different role of Ag such as network modifier and/or former [29]. From the Fig. 2 it can be observed that at the concentration $\leq 1$ at.\% silver mostly acts as a network modifier whereas on further addition of silver, in the current study above 5 at.\%, a part of silver starts to act as network former. The network former property increases with silver concentration and this first response 
to saturate the defect formation and further addition of silver $>15$ at.\%, silver predominantly acts as network former. This is typical behavior of $\operatorname{Ag}$ in similar system $[29,30]$, however very few authors tried to correlate this behavior with the diffusion coefficient nature of such systems $[26,28]$. This is the reason, why the diffusion mechanism of these cations in such systems is not clear and why the question of the ionic conduction mechanism in disordered materials still an active topic of discussion [31, 32].

From Fig. 5 it is clear that the diffusion coefficient increases more rapidly for the samples with low concentration of $\mathrm{Ag}\left(x \leq 1\right.$ at.\%) but still the magnitude of the diffusion coefficient is $\sim 10^{-13}$ $\mathrm{cm}^{2} . \mathrm{s}^{-1}$, whereas samples with higher concentration $(x>5$ at.\%), the magnitude of the $\mathrm{Ag}$ diffusion coefficient varies rapidly. This can be explained on the basis of percolation model of the diffusion coefficient. As mentioned above, the lower concentration of $\operatorname{Ag}(x \leq 1$ at.\%) increases the defects in the matrix, which is responsible for opening more paths for the $\mathrm{Ag}^{+}$ cation conduction. Since the current system $\mathrm{Ag}_{x}\left(\mathrm{Ge}_{16} \mathrm{Sb}_{12} \mathrm{Se}_{72}\right)_{100-x}$ is the selenium rich one, there is a higher probability of breaking of the Se-Se homopolar bonds (which are comparatively weaker than the Ge-Se hetero bonds) and formation of $\mathrm{Se}^{-}$and $\mathrm{Se}^{+}$defect sites and/or $2 \mathrm{Se}^{\cdot}$ radicals. The $\mathrm{Ag}$ atoms possibly transfer the electrons to $\mathrm{Se}^{+}$making it neutral, i.e. the defects in the sites are mostly $\mathrm{Se}^{-}$and ill coordinated $\mathrm{Se}^{\circ}$. Since the concentration of $\mathrm{Ag}$ is smaller ( $x \leq 1$ at.\%), the formation of $\mathrm{Se}^{-}$is also low, i.e., the distance between two neighboring $\mathrm{Se}^{-}$or between two $\mathrm{Se}$ radicals as well as the distance between two neighboring $\mathrm{Ag}^{+}$is expected to be much higher. This higher distance of the $\mathrm{Se}^{-} / \mathrm{Se}^{*}$ excludes the possibility of hopping of the $\mathrm{Ag}^{+}$cation between the sites in the neighborhood of the $\mathrm{Se}^{-} / \mathrm{Se}^{*}$ sites and higher distance between the $\mathrm{Ag}^{+}$cations exclude the possibility of self-blocking. The opening of longer paths and exclusion of hopping possibility, the best choice to the $\mathrm{Ag}^{+}$cations gives to percolate through the opening sites. The driving force for the percolation of the $\mathrm{Ag}^{+}$cations for these low Ag concentrated system is the applied potential. Due to the higher distance between the neighboring $\mathrm{Se}^{-} / \mathrm{Se}^{*}$ sites, these $\mathrm{Se}^{-} / \mathrm{Se}^{*}$ sites act as trapping centers for the $\mathrm{Ag}^{+}$cations and are thus responsible for slow diffusion. The lower defect concentration due to the lower $\mathrm{Ag}$ concentration opens less number of channels/path compared to the samples with high concentration of $\mathrm{Ag}$, the $\mathrm{Ag}^{+}$cations need to find the path to reach the negative electrode. This path might be longer as well as might not be straight, so, the $\mathrm{Ag}^{+}$ions sometimes have to diffuse in the direction away from the electrode, i.e., opposite to the driving force, thus causing further reduction of the diffusion coefficient value. All these factors are responsible for the decrease of the diffusion coefficient magnitude as well as the increase of the activation energy of the diffusion coefficient in the samples with low concentration of Ag.

However, in the case of $x>5$ at.\%, high concentration of $\mathrm{Ag}$ is responsible for the high concentration of defects. This makes the distance between the neighboring $\mathrm{Se}^{-}$ions as well as $\mathrm{Se} \cdot$ radicals close enough to act as hopping sites for $\mathrm{Ag}^{+}$cations. This means that the $\mathrm{Se}^{-}$ion and $\mathrm{Se}$ ' radical sites, which act as a trapping center in the samples with low $\mathrm{x}$, play an opposite role in the samples with high $x$ and playing a positive role for increasing of the diffusion coefficient (decreasing activation energy of the diffusion coefficient). This means that the current studied 
samples having $\mathrm{Ag}$ concentration $x>5$ at.\%, the diffusion of the $\mathrm{Ag}^{+}$cation mainly occur by hopping process. The large number of defects opens a large number of channels also helps in shortening the distance between the $\mathrm{Ag}^{+}$ion and the electrode and further help to decrease the activation energy.

However, in much higher concentrated Ag doped samples, i.e. $x>15$ at.\%, as mentioned earlier Ag starts to dominate his role as a network former, but from Fig. 5 it was observes that, there is a higher number of the mobile ions (i.e. network modifier $\mathrm{Ag}^{+}$) present in the matrix in the case of $x=20$ at.\% than $x=15$ at.\% suggest that not all Ag participate as a network former role. Still, due to the higher number of $\mathrm{Ag}$ participate as a network former responsible for the reduction of the defects in the matrix and already confirmed by thermal analysis. Due to the decrease of the defects, a decrease of the diffusion coefficient can be expected, which is in agreement with Fig. 5, where slight slope change is observed when going from $x=15$ at.\% to 20 at.\%. Even though there is a slight decrease of the slope, the diffusion coefficient of $\mathrm{Ag}_{20}$ is higher than the diffusion coefficient of $\mathrm{Ag}_{15}$. This increase of the diffusion coefficient can be explained as, due to number of increase of $\mathrm{Ag}^{+}$ions, which decreases the distance between $\mathrm{Ag}^{+}$ions much lower, which responsible for generating repulsive interactions between them. This repulsive interaction mentioned in literature as a self-blocking nature [26, 33] i.e. negative impact on the diffusion coefficient, but according to our observation it is contradictory. As the decrease of the defects and addition of self-blocking nature, it is expected to decrease of the diffusion coefficient much lower (less or equal to $\mathrm{Ag}_{15}$ ) but this is contradictory to current observation. This contradiction is due to the wrong assumption that the repulsive interaction, act as a selfblocking nature to $\mathrm{Ag}^{+}$ions. We propose that; the repulsive forces affect positive impact on the diffusion coefficient. As driving force of $\mathrm{Ag}^{+}$ions is electrode potential, concentration gradient

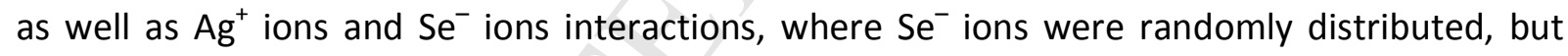
electrode potential is directional force, which makes the $\mathrm{Ag}^{+}$diffusion towards the negative electrode. As all $\mathrm{Ag}^{+}$ions diffusion directions towards the negative electrode, the surrounding $\mathrm{Ag}^{+}$ions repulsive interactions push the $\mathrm{Ag}^{+}$ion towards the negative electrode i.e. decreases the overall activation energy of the diffusion coefficient. The diffusion coefficient in much higher Ag concentrated samples ( $\mathrm{Ag}_{20}$ in the studied system) even though do not show selfblocking nature, it still follows the correlated walk diffusion. Such correlated motion/diffusion were used in the literature for different kind of materials including glasses to study the conduction mechanism of ions [26, 33-36].

\subsubsection{Temperature dependent impedance study}

To observe the temperature dependent conductivity behavior of these samples, i.e. from $\mathrm{Ag}_{0}$ to $\mathrm{Ag}_{20}$, the measurements were carried out in the temperature range from 295 to $368 \mathrm{~K}$ and in the frequency range from $1 \mathrm{~Hz}$ to $50 \mathrm{kHz}$ with the applied input voltage of $0.1 \mathrm{~V}$.

The samples $\mathrm{Ag}_{0}, \mathrm{Ag}_{0.2}, \mathrm{Ag}_{0.4}$ and $\mathrm{Ag}_{0.6}$ shows that their conductivity at low temperature $(<368$ $\mathrm{K}$ ) is beyond the measured instrument limit, that's why the temperature dependence behavior was studied in samples $A g_{0.8}$ to $A g_{20}$. The obtained impedance data $Z_{1}$ vs $Z_{2}$, similar to previous section were first converted to a real $\left(\rho_{1}\right)$ and imaginary part $\left(\rho_{2}\right)$ of resistivity and plotted in 
the form of complex impedance plot (not shown here). The resistivity data were further converted into real $\sigma_{1}$ and imaginary part $\sigma_{2}$ of conductivity. The conductivity with RW model fitting plotted as a function of applied frequency, shown in supplementary Fig. S3 as a case example.

The obtained total conductivity was plotted against the reciprocal of temperature. The conductivity data of all samples (from $\mathrm{Ag}_{0.8}$ to $A g_{20}$ ) are shown in Fig. 6.

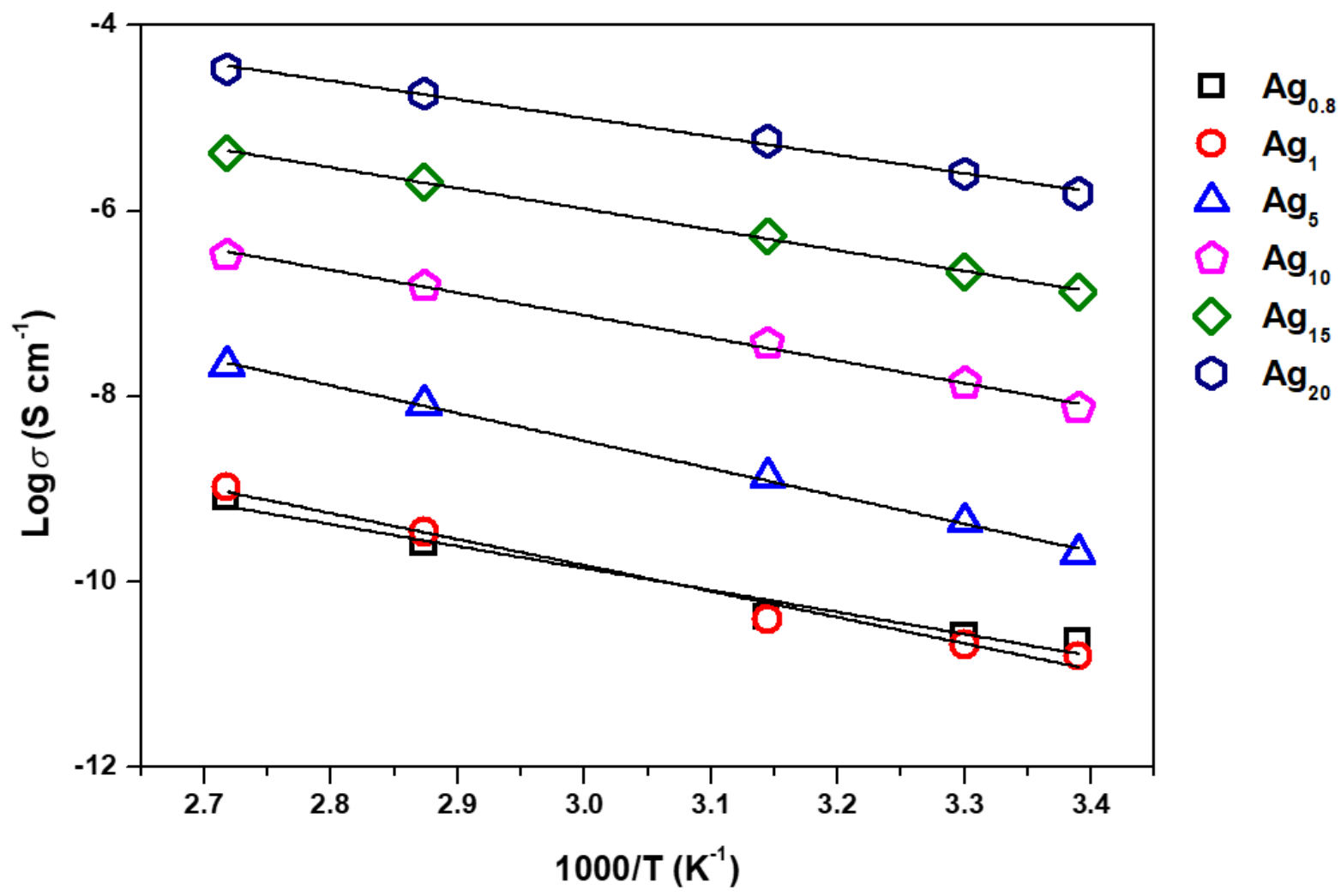

Fig. 6 The temperature dependence of $\sigma_{T}$. The open circles represent the experimental $\sigma_{T}$. The solid line represents the fitting to Arrhenius Eq. (4).

As, shown in Fig. 6, the conductivity data all samples follows Arrhenius eq. (4),

$\sigma_{T}=\sigma_{0} e^{\frac{E_{a}}{k T}}$

where $\sigma_{0}$ is the pre-exponential factor, $E_{a}$ is the activation energy and $\mathrm{k}$ is the Boltzmann constant.

The activation energies calculated from the Arrhenius fitting of the experimental data are given in Table 1.

Table 1 Activation Energies $\left(E_{a}\right)$ of the samples calculated from Arrhenius Eq. 4. 


\begin{tabular}{ll}
$\begin{array}{l}\text { Sample } \\
\text { Name }\end{array}$ & $E_{a}(\mathrm{eV})$ \\
\hline $\mathrm{Ag}_{0.8}$ & 0.47 \\
$\mathrm{Ag}_{1}$ & 0.56 \\
$\mathrm{Ag}_{5}$ & 0.59 \\
$\mathrm{Ag}_{10}$ & 0.48 \\
$\mathrm{Ag}_{15}$ & 0.44 \\
$\mathrm{Ag}_{20}$ & 0.39 \\
\hline
\end{tabular}

From Table 1, it can be observed that the activation energy $(E a)$ first increases from sample $\mathrm{Ag}_{0.8}$ to $\mathrm{Ag}_{5}$ and from $\mathrm{Ag}_{10}$, it starts to decrease. The increase of activation energy up to $\mathrm{Ag}_{5}$ sample, i.e. Ag concentration up to 5 at.\% and later decreases in high Ag concentrated samples are in good agreement with the explanation given from Fig. 5. It can be further explained as, the activation energy increases in lower $\mathrm{Ag}$ concentrated samples from $\mathrm{Ag}_{0.8}$ to $\mathrm{Ag}_{5}$ even though the Ag concentration increases from 0.8 at.\% to 5 at.\% due to the ionic conduction mainly occur via percolation path. It is expected that, the increase of Ag concentration increases the defects in such low Ag doped system (since the Ag act as a network modifier), which act as a trapping centers and responsible for the increase of activation energy.

In the latter case, i.e. from $\mathrm{Ag}_{5}$ samples ( $\mathrm{Ag} 5$ at.\% and above) the decrease of activation energy mainly due to changes in the mechanism of ion conduction i.e. from percolation conduction to hopping conduction. However, in much higher $\mathrm{Ag}$ doped sample case, i.e. in $\mathrm{Ag}_{20}$, the activation energy shows lowest value and even though from Fig. 2, the defects in sample decreases. This gives the confirmation to our earlier statement that, the repulsive nature of $\mathrm{Ag}^{+}$ions due to much shorter distance in high Ag doped samples (in the current study Ag 20 at.\%) doesn't act as a self-blocking nature but helps to enhance the conduction via the correlated walk. Such behavior of $\mathrm{Ag}+$ ions at high concentration we can say as a self-push nature. All these observations confirms that, in the current studied system diffusion mechanism dominates the total conductivity behavior over the concentration of the mobile ions $(N)$. This will be further confirmed in the following section.

From RW model fitting of the temperature dependent sample (a case example is shown in Fig. S3), the calculated number of the mobile ions $(N)$ and the diffusion coefficient $(D)$ using eq. 2 and eq. 3 respectively. The obtained values were plotted as a function of the reciprocal of temperature shown in Fig. 7a and $7 \mathrm{~b}$ respectively. 

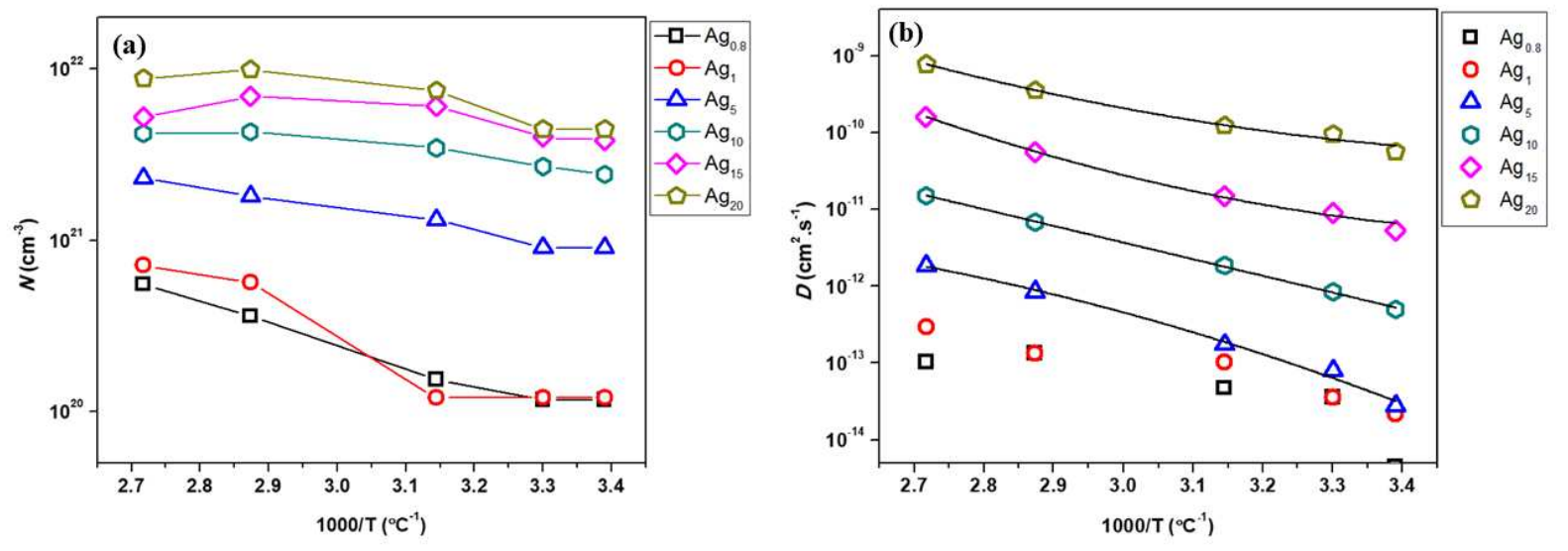

Fig. 7 a) The concentration of the mobile ions $(N)$ vs reciprocal of temperature, b) diffusion coefficient $(D)$ vs reciprocal of temperature, in both a) and b) the open symbol represents the respective figs. calculated from RW model fitting to experimental data and the solid line in a) is the guideline for eye whereas in fig. b) exponential fit to the eq. 5 .

The concentration of the mobile ions $(N)$ and the diffusion coefficient $(D)$ can be described with their temperature dependence by the following exponential laws:

$N=N_{0} \mathrm{e}^{\left(\frac{-E_{N}}{R T}\right)}$ and $D=D_{0} \mathrm{e}^{\left(\frac{-E_{D}}{k_{B} T}\right)}$

Where $N_{0}, D_{0}$ are the pre-exponential factor, $E_{N}, E_{D}$ is the activation energies of the $N$ and $D$ respectively and $R$ and $k_{B}$ have their usual meanings.

Fig. 7a shows the concentration of the mobile ions $(N)$ calculated using RW model fit to the experimental data of conductivity (a case example is shown in Fig. S3). As, it can be observed in Fig. 7a, the $N$ is constant for low temperature up to $318 \mathrm{~K}$ and starts to increase at higher temperature indicating that, the trapped ions are strongly bonded and does not activate until $318 \mathrm{~K}$. This is the reason the data does not fit to the Eq 5. However in Fig. 7b, the diffusion coefficient $(D)$ obtained from the RW model fits to the experimental data of conductivity (case example of Fig. S3 and other remaining samples not shown here), shows good fit to the Eq 5 from $\mathrm{Ag}_{5}$ to $\mathrm{Ag}_{20}$ samples. Whereas in case of $\mathrm{Ag}_{0.8}$ and $\mathrm{Ag}_{1}$, the sample shows two different regions of increase of $D$ i.e. for temperature up to $318 \mathrm{~K}$ the slope of the increment is higher and for the higher temperature region from $318 \mathrm{~K}$ to $368 \mathrm{~K}$ the slope of the increment is lower. In the other words, the activation energy is higher for low temperature region and lower for higher temperature. This anomalous behavior is typical for sample diffusion control by the percolation path[26]. In percolation diffusion, the activation energy is higher for low temperature, whereas lower at higher temperature, as the trapped ions also participate in the conduction at high temperature, i.e. the trapping center less effective (due to higher kinetic energies of the mobile ions) and both quantities i.e. the number of ions $(N)$ and the diffusion coefficient $(D)$ increases, this directly affect on the decrease of activation energy $E_{D}$. It is known that, the total activation energy $E_{\mathrm{a}}$ of conductivity is the sum of activation energies of 
concentration of the mobile ions $\left(E_{N}\right)$ and the diffusion coefficient $\left(E_{\mathrm{D}}\right)$ as shown in following eq 6.

$E_{\mathrm{a}}=E_{\mathrm{N}}+E_{\mathrm{D}}$

From Fig. $7 \mathrm{a}$ and $7 \mathrm{~b}$, it can be observed that, only $D$ follows eq 5 , in other words $E_{\mathrm{N}} \approx 0$. This means, in eq $6, E_{\mathrm{a}}$ is predominantly depends upon $E_{\mathrm{D}}$. This confirms our earlier statement that, the ionic conductivity of the studied samples predominantly controls by the diffusion mechanism.

From Fig. 7b using eq 5 , calculated $E_{\mathrm{D}}$ is given in Table 2 .

Table 2 Activation Energies $\left(E_{D}\right)$ of the diffusion coefficient $(D)$ of the samples calculated from Eq. 5

\begin{tabular}{ll} 
Sample & $E_{\mathrm{D}}(\mathrm{eV})$ \\
\hline $\mathrm{Ag}_{5}$ & 0.52 \\
$\mathrm{Ag}_{10}$ & 0.43 \\
$\mathrm{Ag}_{15}$ & 0.42 \\
$\mathrm{Ag}_{20}$ & 0.32 \\
\hline
\end{tabular}

Comparing the values of Table 2 with Table 1, it is clear that, all the activation energy values $E_{D}$ are close to total activation energy $E_{\mathrm{a}}$ values, this further confirms that the $E_{\mathrm{a}}$ value in the current studied system mainly controls by $E_{\mathrm{D}}$ and less dependent on $E_{\mathrm{N}}$. In the other words, the conductivity behavior of the $\mathrm{Ag}_{x}\left(\mathrm{Ge}_{16} \mathrm{Sb}_{12} \mathrm{Se}_{72}\right)_{100-x}$ system mainly depend on the Ag diffusion behavior and less dependent on the concentration of the mobile ions. The lowest value of $E_{\mathrm{D}}$ for $\mathrm{Ag}_{20}$ sample, i.e. $0.32 \mathrm{eV}$ again confirms our earlier statement that, "in high concentrated sample the $\mathrm{Ag}^{+}$repulsive nature doesn't act as a self-blocking way, however the repulsive force helps to decrease the activation energy, i.e. act as a self-push nature." This is a novel observation with a contradiction to literature [26, 37].

It should be noted that, in Fig. $7 \mathrm{~b}$, the sample with low $\mathrm{Ag} \leq 5$ at.\% shows convex behavior whereas higher Ag content $\geq 15$ at.\% shows concave behavior. This anomalous behavior of diffusion coefficient as a function of temperature may be due to the different diffusion mechanism in each case as mentioned earlier and/or due to the sample dominant charge carrier variation from electronic+ionic for low $\mathrm{Ag}$ to pure ionic for higher $\mathrm{Ag}$.

\subsection{Potentiostatic Chronoamperometry}

To distinguish the contribution of electronic and ionic conductivity to the total conductivity, the samples $\mathrm{Ag}_{0.2}$ and $\mathrm{Ag}_{20}$ was further analyzed by potentiostatic chronoamperometry. The same samples which used for impedance analysis were also used for potentiostatic chronoamperometry with gold electrodes as a blocking electrode for $\mathrm{Ag}^{+}$cations. The 
dependence of current on time was recorded for sample $\mathrm{Ag}_{0.2}$ and $\mathrm{Ag}_{20}$ as a case example at $368 \mathrm{~K}$ until the state close to equilibrium was reached; the obtained current data plotted as a function of time and is shown in Fig. 8.

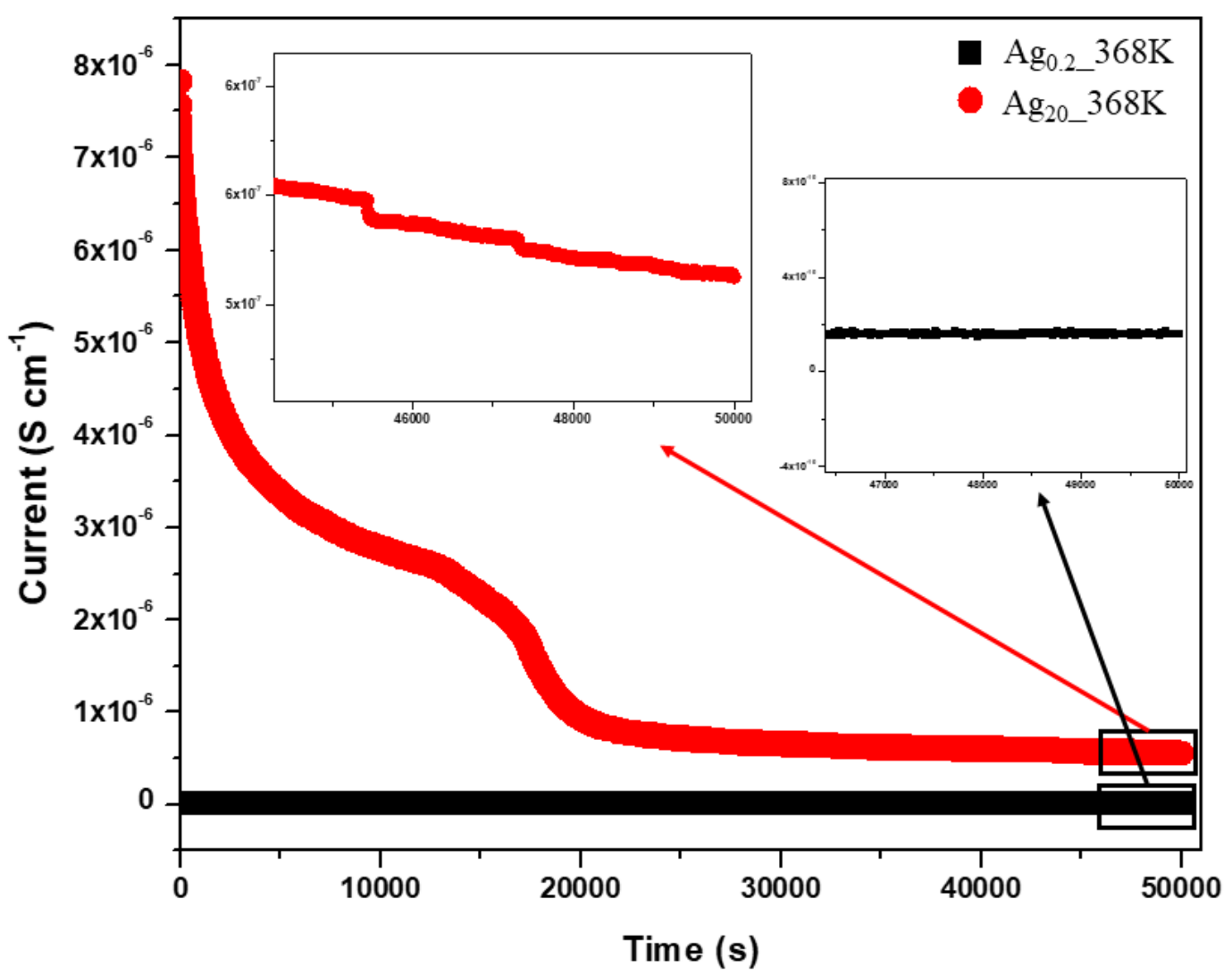

Fig. 8 The potentiostatic current as a function of time. Inset, the magnified images of the marked blocks.

The DC potentiostatic conductivity $\left(\sigma_{\mathrm{dcp}}\right)$ was then calculated from the steady-state current $I_{\infty}$ (at time $\mathrm{t} \rightarrow \infty$ ) according to the following Eq 7,

$\sigma_{d c p}=\frac{I_{\infty} \times l}{U \times A}$

Where $\mathrm{I}$ is the sample thickness/electrode distance, $U$ is the applied voltage and $A$ is the electrode surface area.

When the electrodes are blocking in nature, the $\sigma_{\mathrm{dcp}}$ represents the electronic conductivity of the corresponding sample. The electronic conductivity contribution to the total conductivity was further calculated from $\sigma_{\mathrm{dcp}} / \sigma_{T}$, where $\sigma_{T}$ is the total conductivity obtained from impedance analysis. From the above calculations, the obtained $\sigma_{\mathrm{dcp}}$ for $\mathrm{Ag}_{0.2}, \mathrm{Ag}_{20}$ samples are $1.88 \times 10^{-10}$ and $1.11 \times 10^{-6}{\mathrm{~S} . \mathrm{cm}^{-1}}$ respectively, i.e. the electronic conductivities contribution to the total conductivities are $17 \%$ and $3 \%$ respectively for the sample $\mathrm{Ag}_{0.2}$ and $\mathrm{Ag}_{20}$. $\mathrm{As}$, it can be observed in the insets of Fig. 8 that, the DC current is reached to equilibrium for $\mathrm{Ag}_{0.2}$ sample, however, for $\mathrm{Ag}_{20}$ sample, still shows steady loss, i.e. sample at higher time can reach to further lower 
value at equilibrium i.e. $\mathrm{Ag}_{20}$ sample can show further lower electronic contribution to the total conductivity. This clearly shows the transformation of electronic (hole) to the ionic conducting glasses as $\mathrm{Ag}_{0} 100 \%$ electronic to $\mathrm{Ag}_{20}>97 \%$ of ionic conductivity.

\subsection{Raman Analysis}

To understand the conductivity behavior with structural correlations, all samples were further analyzed by Raman spectroscopy. The obtained Raman data for samples $A_{x}\left(G_{16} S_{12} S_{12} e_{700-x}\right.$ (where $x=0$ to 20) are plotted as a function of wavenumber and shown in Fig. 9.

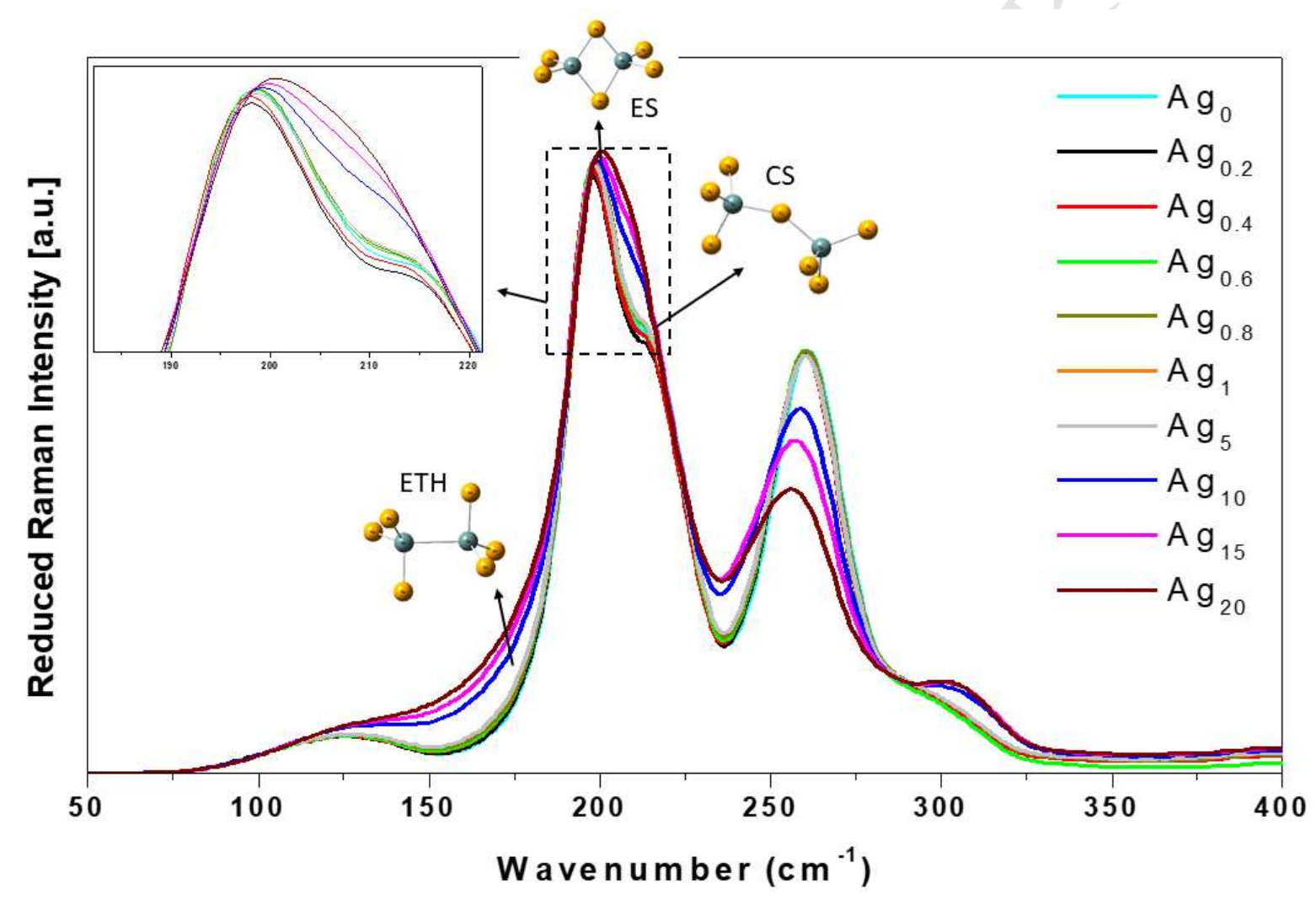

Fig. 9 Reduced Raman spectra of $\mathrm{Ag}_{x}\left(\mathrm{Ge}_{16} \mathrm{Sb}_{12} \mathrm{Se}_{72}\right)_{100-x}$ (where $x=0$ to 20), inset the magnified image of dotted block. The orange colored balls and cyan colored balls in ball stick models are Se and $\mathrm{Ge}$ respectively.

Fig. 9 shows the typical behavior of the Se rich GeSbSe system [23, 38]. The most intense peak at $200 \mathrm{~cm}^{-1}$ is due to stretching vibrations of the Ge-Se bond of the edge sharing $\mathrm{GeSe}_{4 / 2}$ tetrahedra entity. The asymmetric peak clearly reveals the presence of two different contributions. First, It can be observed in the magnified image that the most intense peak is shifted to lower wavenumbers with the addition of $\mathrm{Ag}$ from $201 \mathrm{~cm}^{-1}$ for $\mathrm{Ag}_{20}$ down to $198 \mathrm{~cm}^{-1}$ for pure $\mathrm{Ge}_{16} \mathrm{Sb}_{12} \mathrm{Se}_{72}$ glass. At the same time, it can be also observed in Fig. 9 that the width of 
the peak and intensity also increase with addition of $\mathrm{Ag}$ especially for samples $\mathrm{Ag}_{10}$ to $A g_{20}$. The peak shift from $198 \mathrm{~cm}^{-1}$ to $201 \mathrm{~cm}^{-1}$ and the increase peak width and intensity can be explained on the basis of the structural transformation. The current studied system $\mathrm{Ag}_{x}\left(\mathrm{Ge}_{16} \mathrm{Sb}_{12} \mathrm{Se}_{72}\right)_{100-x}$ has a considerable amount of $\mathrm{Se}$ in comparison to $\mathrm{Ge}$ and $\mathrm{Sb}$. The bonding between $\mathrm{Se}$ and $\mathrm{Sb}$ is characterized by a peak around $195 \mathrm{~cm}^{-1}$ attributed to $\mathrm{Sb}$-Se stretching vibrations of $\mathrm{SbSe}_{3 / 2}$ pyramids [38]. Ge more likely to form corner sharing tetrahedra than edge sharing tetrahedra [23]. The peak at $213 \mathrm{~cm}^{-1}$ is due to stretching vibrations of Ge-Se/Sb-Se corner sharing $\mathrm{GeSe}_{4 / 2} / \mathrm{SbSe}_{4 / 2}$ tetrahedra entity. So, the peak at $198 \mathrm{~cm}^{-1}$ for low $\mathrm{Ag}$ concentrated sample is due to overlap of the peak at $195 \mathrm{~cm}^{-1}$ and peak at $200 \mathrm{~cm}^{-1}$ of SbSe $3 / 2$ pyramidal and $\mathrm{GeSe}_{4 / 2}$ edge sharing tetrahedral entities, respectively. The overlapped peak generally appears at $200 \mathrm{~cm}^{-1}$ in the GeSbSe system [39] but in the current case, the concentration of $\mathrm{GeSe}_{4 / 2}$ edge sharing (ES) tetrahedral entity is weak for low Ag concentrated sample, which leads to the overlap peak shifted to lower wavenumber i.e. at $198 \mathrm{~cm}^{-1}$. The shifting of $198 \mathrm{~cm}^{-1}$ to $201 \mathrm{~cm}^{-1}$ it is assumed that the addition of $\mathrm{Ag}$ increases the defects mainly by breaking Se-Se homopolar bonds but for the samples with a high Ag concentration (> 5 at. \%), it starts to degrade $\mathrm{GeSe}_{4 / 2} \mathrm{CS}$ tetrahedra as well, leaving less Se available for Ge$\mathrm{Se} / \mathrm{Sb}$-Se bond formation, this creates more ES GeSe $4 / 2$ tetrahedra. Ag mainly breaks Se - Se homopolar bond and this is confirmed from the decrease of peak intensity located at $260 \mathrm{~cm}^{-1}$, which is attributed due to the $\mathrm{Se}-\mathrm{Se}$ bond-stretching vibration of the disordered $\mathrm{Se}_{\mu}$ chains or rings [17]. The peak at $303 \mathrm{~cm}^{-1}$ is due to the asymmetric vibration modes of $\mathrm{GeSe}_{4 / 2}$ tetrahedra and the appearance of a peak for samples having $\mathrm{Ag}$ concentration $>5$ at.\% confirms that, these asymmetric vibrations mainly arising from ES $\mathrm{GeSe}_{4 / 2}$ tetrahedra. In Fig. 9, it can be also observed that the peak broadening for high Ag concentrated sample ( $>5$ at.\%) also appear for peak $200 \mathrm{~cm}^{-1}$ towards lower wavenumber as well. This is due to the overlap of new peak $170 \mathrm{~cm}^{-1}$, which is attributed to $\mathrm{Ge}-\mathrm{Ge}$ and $\mathrm{Sb}-\mathrm{Sb}$ homopolar bond stretching for $\mathrm{Se}_{3} \mathrm{Ge}(\mathrm{Sb})-$ $\mathrm{Ge}(\mathrm{Sb}) \mathrm{Se}_{3}$ ethane (ETH) like molecule. As the peak width increases in the case of $\mathrm{Ag}>5$ at. \% confirms that, the ETH like molecule formation occur in high Ag concentrated samples. This also proves our earlier statement that, in high $\mathrm{Ag}$ concentrated samples, $\mathrm{Ag}^{+}$cations, not only breaks $\mathrm{Se}-\mathrm{Se}$ bonds, but also $\mathrm{Ge}$ - Se bonds of $\mathrm{CS} \mathrm{GeSe}_{4 / 2}$ tetrahedra. This is in good accordance with the shift of $260 \mathrm{~cm}^{-1}$ to $255 \mathrm{~cm}^{-1}$ in high Ag concentrated samples. The peak at $255 \mathrm{~cm}^{-1}$ arises from vibration modes of $\mathrm{Ge}-\mathrm{Ge}$ bonds of $\mathrm{Se}_{3} \mathrm{Ge}(\mathrm{Sb})-\left(\mathrm{GeSe}_{2}\right)_{0.1}-\mathrm{Ge}\left(\mathrm{Sb}_{3} \mathrm{Se}_{3}\right.$ [38].

From all these Raman features, it is confirmed that, the $\mathrm{Ag}$ concentration 5 at. \% is the threshold limit for the defect formation due to Se - Se bond breaking. Above 5 at. \% of $\mathrm{Ag}, \mathrm{Ag}^{+}$ cations start to break even $\mathrm{Ge}$ - Se heteronuclear bonds also in addition to $\mathrm{Se}-\mathrm{Se}$ homopolar bond. It is observed that, the breaking of $\mathrm{Ge}$ - Se heteronuclear bonds, mainly from CS GeSe $\mathrm{C}_{4 / 2}$ tetrahedra and forming more $\mathrm{ES} \mathrm{GeSe}_{4 / 2}$ tetrahedra as well as $\mathrm{Ge}-\mathrm{Ge}$ homopolar bonds. This confirms that, the conductivity as well as the diffusion coefficient increase in the case of samples having $\mathrm{Ag}>5$ at. \% are due to hopping mechanism, as it can be expected from above Raman features that, the hopping sites are close enough for $\mathrm{Ag}^{+}$ions hop. The surprising feature that, from TGA and impedance analysis, it is found that, $\mathrm{Ag}_{20}$ sample has slight different features due to Ag dual behavior, i.e. network modifier and network former, such feature didn't detected in Raman data of Fig. 9. This might be due to less sensitivity of Ag - Se molecular vibrations [40]. 
The observation of the transformation of $\mathrm{CS} \mathrm{GeSe}{ }_{4 / 2}$ tetrahedra to $\mathrm{ES} \mathrm{GeSe}_{4 / 2}$ tetrahedra as a function of Ag concentration has been made first time to the author's knowledge. Also, the formation of homopolar bonds, $\mathrm{Se}^{-}$ions and Se with dangling bonds ( $\left.\mathrm{Se}^{-}\right)$acts as defects in the matrix for high $\mathrm{Ag}$ concentrated samples, helping $\mathrm{Ag}^{+}$ions diffuse faster by reducing the activation energy, which directly affects the conductivity behavior of the studied samples. Since, mentioned in an earlier section, the diffusion is predominant for influencing the conductivity behavior over the concentration of the mobile ions in the current studied chalcogenide glassy system.

From current study, it can be observed that, the RW model gives the important information, to understand the ion conduction mechanism in such disordered materials than the conventional equivalent electric circuit (EEC) model. Finally, the current study not only helps to understand the percolation behavior of the $\mathrm{Ag}^{+}$ions in $\mathrm{Ge}_{16} \mathrm{Sb}_{12} \mathrm{Se}_{72}$ chalcogenide glassy matrix, but it also helps to understand the diffusion/conductivity mechanism of all similar disordered systems, which is really important to enhance the current ion conducting technologies optimize to farther higher level.

\section{Conclusion}

In the present article, we have studied the percolation behavior of $\mathrm{Ag}^{+}$cations in $\mathrm{Ag}_{x}\left(\mathrm{Ge}_{16} \mathrm{Sb}_{12} \mathrm{Se}_{72}\right)_{100-x}$ matrix. It is observed that, the $\mathrm{Ag}$ loading capacity in the studied matrix $\mathrm{Ge}_{16} \mathrm{Sb}_{12} \mathrm{Se}_{72}$ is $<25$ at.\%, without getting phase separation. The thermal behavior (Tg) varies non-linearly as a function of $\mathrm{Ag}$ concentration.

From the impedance data analysis by RW model found that, the conductivity behavior and diffusion also shows a non-linear trend with $\mathrm{Ag}$ content. Diffusion follows three different mechanisms depending on the concentration of $\mathrm{Ag}$ in the matrix such as for low $\mathrm{Ag}$ concentrated samples $<5$ at. \% occur via percolation path and further increase of Ag $>5$ at. \% the diffusion occur mainly via hopping process. However, for much higher concentrated $\mathrm{Ag}$ samples, i.e. $>15$ at. \%, the diffusion occur via the correlated walk. There is also a novel observation made for correlated walk diffusion that, the repulsive nature of $\mathrm{Ag}^{+}-\mathrm{Ag}^{+}$cations due to decrease of $\mathrm{Ag}^{+}$cation distance in high concentrated $\mathrm{Ag}$ i.e. $>15$ at. \% in the current study does not act as a self-blocking nature. It actually works opposite way i.e. self-push nature. This helps to decrease the activation energy much lower and enhance the diffusion coefficient much higher rate. From Chronoamperometric analysis confirmed that; the system transforms from electronic to the almost pure ionic in nature as $\mathrm{Ag}$ varies from 0 at. \% to 20 at. \%. The structural transformation was observed from Raman analysis, such as for samples having $\mathrm{Ag}$ concentration $<5$ at. $\%$, the $\mathrm{GeSe}_{4 / 2}$ tetrahedra distributed in both edge shared and corner shared way, however, for samples with $\mathrm{Ag}>5$ at. \%, the $\mathrm{GeSe}_{4 / 2}$ transforms mainly to edge shared (ES) tetrahedral and also inducing some $\mathrm{Ge}(\mathrm{Sb})-\mathrm{Ge}(\mathrm{Sb})$ homopolar bonds even in such 
Se rich system. Such structural transformations depending upon Ag concentration confirms the dual role of Ag.

We have also shown that, the RW model gives the important information to understand the more depth information about the ionic conduction in disordered materials than the conventional EEC model.

\section{Acknowledgements}

The author DP would like to thank to Professor Petr Viscor for valuable conversations and comments. This research is being performed using funding received from the project of the Ministry of Education, Youth and Sports, CR, Grant LM2015082 Center of Materials and Nanotechnologies, ED4.100/11.0251 from the Ministry of Education, Youth and Sports of the Czech Republic and European Regional Development Fund-Project "Modernization and upgrade of the CEMNAT" (No. CZ.02.1.01/0.0/0.0/16_013/0001829), project NANOMAT and to the project Czech Technological Agency in project GAMA (Grant No. GAMA02/011) for financial support.

. Also, part of this research was performed at the University of Rennes 1, Rennes, France, with financial support received from "Erasmus +" and "French Mobility Grant" programs. Author 'Deepak Patil' would like to acknowledge, U.S. Department of Energy - Office of Nuclear Energy through the Nuclear Energy University Program under the award DE-NE0008431 and NSF PREM program (DMR-1523611) for financial support during the article writing and discussion.

\section{References}

[1] In: J.-L. Adam, X. Zhang, Editors, Chalcogenide Glasses; Preparation, Properties and Applications, Woodhead Publishing (2014).

[2] S. Cui, C. Boussard-Plédel, J. Troles, B. Bureau, Opt. Mater. Express 6 (2016) (4) 971.

[3] U. Møller, Y. Yu, I. Kubat, C.R. Petersen, X. Gai, L. Brilland, D. Méchin, C. Caillaud, J. Troles, B. Luther-Davies, O. Bang, Opt. Express 23 (2015) (3) 3282.

[4] A.M. Andriesh, Journal of Non-Crystalline Solids 77-78 (1985) 1219.

[5] P. Masselin, E. Bychkov, D.L. Coq, Opt. Lett. 41 (2016) (15) 3507.

[6] A. Zoubir, M. Richardson, C. Rivero, A. Schulte, C. Lopez, K. Richardson, N. Hô, R. Vallée, Opt. Lett. 29 (2004) (7) 748.

[7] C. Vigreux, R. Escalier, A. Pradel, L. Bastard, J.E. Broquin, X. Zhang, T. Billeton, G. Parent, M. Barillot, V. Kirschner, Optical Materials 49 (2015) 218.

[8] B.J. Eggleton, B. Luther-Davies, K. Richardson, Nature Photonics 5 (2011) 141.

[9] D.S. Patil, K. Shimakawa, V. Zima, J. Macak, T. Wagner, Journal of Applied Physics 113 (2013) (14) 143705.

[10] S. Patil Deepak, S. Konale Manisha, J. Kolar, K. Shimakawa, V. Zima, T. Wagner, lonic conductivity study of Lil-Ga2S3-GeS2 chalcogenide glasses using a random-walk approach, Pure and Applied Chemistry (2015), p.249.

[11] W. Yao, S.W. Martin, Solid State Ionics 178 (2008) (33) 1777.

[12] V. Sousa, Microelectronic Engineering 88 (2011) (5) 807.

[13] Y.G. Vlasov, E.A. Bychkov, A.M. Medvedev, Analytica Chimica Acta 185 (1986) 137. 
[14] J.M. Conde Garrido, M.A. Ureña, B. Arcondo, Journal of Alloys and Compounds 495 (2010) (2)

356.

[15] A. Pradel, M. Ribes, Journal of Solid State Chemistry 96 (1992) (1) 247.

[16] M. Popescu, Journal of Optoelectronics and Advanced Materials 7 (2005) (4).

[17] D. Patil, M. Konale, L. Strizik, L. Calvez, D. Le Coq, B. Frumarova, M. Vlcek, T. Wagner, Journal of Materials Science and Engineering 6 (2016) (5-6) 131.

[18] S. Cozic, A. Bréhault, D. Le Coq, T. Usuki, International Journal of Applied Glass Science 7 (2016) (4) 513.

[19] K. Yu, R. Gu, L. Wu, H. Sun, R. Ma, L. Jin, Y. Xu, Z. Xu, X. Wei, Journal of Alloys and Compounds 739 (2018) 892.

[20] J. Zhang, L. Zhang, F. Sun, Z. Wang, IEEE Access 6 (2018) 23848.

[21] F. Zheng, M. Kotobuki, S. Song, M.O. Lai, L. Lu, Journal of Power Sources 389 (2018) 198.

[22] K. Tanaka, Y. Miyamoto, Solid State Ionics 269 (2015) 106.

[23] W.-H. Wei, R.-P. Wang, X. Shen, L. Fang, B. Luther-Davies, The Journal of Physical Chemistry C 117 (2013) (32) 16571.

[24] D.S. Patil, K. Shimakawa, V. Zima, T. Wagner, Journal of Applied Physics 115 (2014) (14) 143707.

[25] S. Sharda, P. Sharma, V. Sharma, IOP Conference Series: Materials Science and Engineering 225

(2017) (1) 012009.

[26] E. Bychkov, V. Tsegelnik, Y. Vlasov, A. Pradel, M. Ribes, Journal of Non-Crystalline Solids 208 (1996) (1) 1.

[27] S. Stehlik, J. Kolar, M. Bartos, M. Vlcek, M. Frumar, V. Zima, T. Wagner, Solid State lonics 181 (2010) (37) 1625.

[28] R. Perriot, B.P. Uberuaga, R.J. Zamora, D. Perez, A.F. Voter, Nature Communications 8 (2017) (1) 618.

[29] M. Mitkova, Y. Wang, P. Boolchand, Physical Review Letters 83 (1999) (19) 3848.

[30] A.T. S. K. Tripathi, G. Singh, J. Sharma, V. Sharma, K. P. Singh, G. S. S. Saini, N. Goyal, Journal of Optoelectronics and Advanced Materials 7 (2005) (4) 2095

[31] A. Bunde, M.D. Ingram, S. Russ, Phys. Chem. Chem. Phys. 6 (2004) (13) 3663.

[32] J.C. Bachman, S. Muy, A. Grimaud, H.-H. Chang, N. Pour, S.F. Lux, O. Paschos, F. Maglia, S. Lupart, P. Lamp, L. Giordano, Y. Shao-Horn, Chemical Reviews 116 (2016) (1) 140.

[33] S.H. Jacobson, M.A. Ratner, A. Nitzan, The Journal of Chemical Physics 78 (1983) (6) 4154.

[34] C.S. Zhang W, Li N, Zhang Jz, Chen W, PLoS ONE 9 (2014) (1).

[35] L.W. Barr, M.A.M.I. Elmessiery, Nature 281 (1979) 553.

[36] S. Lunghammer, D. Prutsch, S. Breuer, D. Rettenwander, I. Hanzu, Q. Ma, F. Tietz, H.M.R. Wilkening, Scientific Reports 8 (2018) (1) 11970.

[37] H. Jain, N.L. Peterson, H.L. Downing, Journal of Non-Crystalline Solids 55 (1983) (2) 283.

[38] Y.-L. Gan, L. Wang, X.-Q. Su, S.-W. Xu, X. Shen, R.-P. Wang, Journal of Raman Spectroscopy 45 (2014) (5) 377.

[39] E. Baudet, C. Cardinaud, A. Girard, E. Rinnert, K. Michel, B. Bureau, V. Nazabal, Journal of NonCrystalline Solids 444 (2016) 64.

[40] S.K. Saikin, R. Olivares-Amaya, D. Rappoport, M. Stopa, A. Aspuru-Guzik, Phys. Chem. Chem. Phys. 11 (2009) (41) 9401. 
Highlights:

Ionic conductivity behavior was predominantly depend upon diffusion behavior Percolation mechanism of $\mathrm{Ag}^{+}$found concentration dependent

Self-push nature of mobile ions observed at high concentration

Concentration dependent structural transformation observed in base glass structure 